\title{
Bronchiectasis in Chronic Obstructive Airway Disease: More than a Comorbidity?
}

Miguel Ángel Martínez-García, MD, PhD, María José Selma Ferrer, MD, and Enrique Zaldívar Olmeda, MD

\section{ABSTRACT}

Beyond the bronchial dilatations associated with age, several studies have documented a higher prevalence of bronchiectasis in patients with severe asthma or chronic obstructive pulmonary disease (COPD). Perhaps COPD or asthmatic patients with bronchiectasis represent a clinical phenotype characterised by greater clinical and functional severity, a higher number of exacerbations and, in the case of COPD, greater colonisation by potentially pathogenic microorganisms and probably a poor prognosis. Although international guidelines recommend that the two diseases are treated separately when they coexist, patients with COPD or asthma associated with bronchiectasis may benefit from specific treatments, such as long-term antibiotics, physiotherapy or macrolides. It is biologically plausible that severe asthma, and especially severe COPD, are related to de novo bronchiectasis, but no study has yet demonstrated any cause-effect relationship. Early diagnosis and treatment of bronchiectasis in COPD and asthma could be crucial to improve their prognosis. This relationship poses an interesting scientific challenge for the future. (BRN Rev. 2017;:178-91) Corresponding author: Miguel Ángel Martínez-García, mianmartinezgarcia@gmail.com

Key words: Alpha-1 antitrypsin deficiency. Asthma. Bronchiectasis. COPD. Emphysema. 


\section{INTRODUCTION}

Bronchiectasis can be considered the final stage in the damage to the lung caused by a range of diseases, both respiratory and systemic. The most recent guidelines issued by the Spanish Society of Pneumology (2017) on the diagnosis and treatment of bronchiectasis define it as "a chronic inflammatory bronchial disease with irreversible dilatation of the bronchial lumen that can have various causes. Clinically, it is usually associated with coughing and chronic expectoration, as well as recurrent exacerbations of an infectious nature. It can coincide with chronic bronchial infection and a progressive decline in lung function; all of this can lead to a deteriorated quality of life and increased morbidity and mortality" (in press). This definition tends to exclude bronchial dilatations associated with old age and the traction bronchiectasis commonly associated with destructive interstitial processes in the lung and with ruptured anchors in the bronchial wall resulting from pulmonary emphysema; this omission can be explained by the particular characteristics of these disorders (negligible symptoms and lack of any clear inflammatory or infectious substrate that can be evaluated by the degree of bronchial wall thickening) ${ }^{1}$. Several chronic respiratory diseases (usually those with an inflammatory profile) can trigger (or be associated with) bronchiectasis. Two of them in particular have attained special prominence in recent years due to their epidemiological impact: chronic obstructive pulmonary disease (COPD), including alpha- 1 antitrypsin deficiency ( $\alpha 1-\mathrm{ATD})^{2,3}$ and asthma ${ }^{4}$. However, the associations between COPD/asthma and bronchiectasis are not devoid of controversy, for various reasons. Firstly, these diseases are clinically similar, which means that their diagnosis is often confused; secondly, they are common diseases and can therefore coexist without any need for a link between them (for example, in a patient with COPD and bronchiectasis in the upper lobes as a result of a previous pulmonary tuberculosis); and, finally, because there is no definitive proof that COPD and asthma cause bronchiectasis per se, although this does seem biologically plausible. This review refers exclusively to non-cystic fibrosis bronchiectasis, and will devote special attention to the relationships between bronchiectasis and both COPD and asthma; we shall examine the prevalence of bronchiectasis in patients with COPD or asthma and its degree of association with these diseases, as well as its impact and therapeutic repercussions, and, finally, the challenges facing us in the future.

\section{BRONCHIECTASIS IN PATIENTS WITH COPD}

\section{Prevalence}

Bronchiectasis is a complex and heterogeneous disease that is ideally suited for precision medicine because it likely represents a continuum of different diseases that may share biological mechanisms (often referred to as "endotypes") and present similar clinical and prognostic (often referred to as "phenotypes") that require an individualized therapeutical approach based on the identification of treatable traits in each patient $t^{5}$. The gold standard for diagnosing bronchiectasis is high-resolution computed tomography (HRCT) of the chest. There are various criteria for a radiological diagnosis, the most used probably being the Naidich criteria, based on a broncho-arterial ratio $>1$, a lack of tapering on the 
periphery of a bronchus and the existence of dilated bronchia less than $1 \mathrm{~cm}$ from the parietal or mediastinal pleura ${ }^{6}$. However, any definition of bronchiectasis as an airway disorder requires a compatible clinical picture (usually productive cough). In this respect, bronchiectasis associated with interstitial lung disease ("traction bronchiectasis") or dilated bronchia typical of the elderly should not be considered "true" bronchiectasis". Moreover, bronchiectasis is usually associated with bronchial wall thickening, as a consequence of bronchial inflammation. Some authors have considered bronchiectasis without a compatible clinical picture to be "dry bronchiectasis". It is important to stress that the presence of a spirometric pattern of airway obstruction (forced expiratory volume in one second $\left(\mathrm{FEV}_{1}\right) /$ forced vital capacity $(\mathrm{FVC})<0.70)$ is not essential for a diagnosis of bronchiectasis (in contrast with COPD), even though this is the functional pattern most frequently seen in bronchiectasis ${ }^{7,8}$.

If we accept the broad definition of bronchiectasis as abnormal bronchial dilatations, then there are no reliable data on its prevalence in patients with COPD. Depending on the methodology used in the various studies to date, the reported prevalence ranges from 2 to $72 \%{ }^{9-24}$. Table 1 shows some of the common causes of an under- or overestimation of the presence of bronchiectasis in patients with COPD. Overestimations are probably more frequent, largely due to: the inclusion of patients in a severe or exacerbatory phase; the appearance of dynamic bronchial dilatations typical of patients with COPD; the selective application of HRCT; asymptomatic bronchiectasis related to (or confused with) emphysema; and the presence of bronchial dilatations typical of the elderly (reported in up to $20 \%$ of individuals aged above
TABle 1. Reasons for the discrepancies observed in the various studies of the prevalence of bronchiectasis in patients with chronic obstructive pulmonary disease

\begin{tabular}{|l}
$\begin{array}{l}\text { Inclusion of bronchiectasis of any aetiology, not only that } \\
\text { of unknown origin }\end{array}$ \\
\hline Inclusion of non-consecutive COPD patients \\
\hline Non-consecutive performance of HRCT \\
\hline Bronchial dilatations due to old age \\
\hline Dynamic bronchial dilatations secondary to COPD \\
\hline Inclusion of patients with COPD only in an exacerbation phase \\
\hline Inclusion of traction bronchiectasis (e.g., secondary to \\
emphysema or interstitial disorders) \\
\hline Performance of HRCT with an objective other than the diagnosis \\
or impact of bronchiectasis (e.g., quantification of emphysema) \\
\hline Diagnostic errors (e.g., emphysema, pulmonary cysts) \\
\hline False bronchiectasis in cases of hypoxic vasoconstriction \\
\hline Lack of identification in pulmonary hypertension \\
\hline CT without high-resolution algorithms \\
\hline Inclusion of patients with bronchiectasis in only one segment \\
of the lung
\end{tabular}

COPD: chronic obstructive pulmonary disease; CT: computed tomography; HRCT: hugh-resolution computed tomography.

60-65 years). It must not be forgotten however, that there are other reasons for underestimating the presence of bronchiectasis: the use of computed tomography (CT) without high-resolution algorithms, or of HRCT for purposes other than evaluating the presence of bronchiectasis, such as quantifying emphysema ${ }^{3,25,27}$.

It is possible that the most reliable evaluation of the prevalence of bronchiectasis in COPD patients from the seventeen, methodologically diverse, studies published to date should focus on those with the most appropriate methodology (albeit not entirely free of problems): an objective to evaluate bronchiectasis of unknown origin in consecutive COPD patients in a clinically stable phase who all underwent a prospective HRCT scan. These criteria are 
TABLE 2. Studies designed to evaluate bronchiectasis of unknown origin in consecutive COPD patients in a clinically stable phase who all underwent a prospective high-resolution computed tomography (HRCT) scan

\begin{tabular}{|c|c|c|c|c|c|c|}
\hline Author (yr) & n & COPD & Study design & $\begin{array}{c}\text { Bronchiectasis } \\
\text { criteria }\end{array}$ & $\begin{array}{c}\text { Bronchiectasis } \\
\text { prevalence }\end{array}$ & $\begin{array}{l}\text { Lower } \\
\text { lobes }\end{array}$ \\
\hline Patel et al. (2004) & 54 & Moderate-to-severe & Prospective & Naidich & $50 \%$ & $66.7 \%$ \\
\hline $\begin{array}{l}\text { Martinez-Garcia et al. } \\
\text { (2011) }\end{array}$ & 92 & Moderate-to-severe & Prospective & Naidich & $\begin{array}{c}\mathbf{5 7} \% \\
34.7 \% \text { in moderate } \\
72.5 \% \text { in severe }\end{array}$ & $60.4 \%$ \\
\hline Arram OA et al. (2012) & 69 & Moderate-to-severe & Cross-sectional & Naidich & $\begin{array}{c}\mathbf{4 7 . 8} \% \\
31.1 \% \text { moderate } \\
62.2 \% \text { severe }\end{array}$ & $67 \%$ \\
\hline Stewart JI et al. (2012) & 3752 & GOLD II-IV & Prospective & Visual assessment & $\begin{array}{c}\mathbf{2 0 . 8} \% \\
18.8 \% \text { GOLD II } \\
24 \% \text { GOLD III-IV }\end{array}$ & -- \\
\hline $\begin{array}{l}\text { Martinez-Garcia et al. } \\
\text { (2013) }\end{array}$ & 201 & Moderate-to-severe & Prospective & Naidich & $57.2 \%$ & $81 \%$ \\
\hline Tulek (2013) & 80 & All stages & Cross-sectional & Naidich & $\begin{array}{c}\mathbf{3 3 . 8} \% \\
40 \% \text { in moderate-to-severe }\end{array}$ & -- \\
\hline Doria et al. (2016) & 65 & All stages & Retrospective & Bhalla & $33.8 \%$ & -- \\
\hline
\end{tabular}

COPD: chronic obstructive pulmonary disease; GOLD: global initiative for chronic obstructive lung disease.

satisfied by the seven studies ${ }^{9,12,14-16,20,23}$ in table 2, which gives us a narrower range of prevalence: $20.8-57.2 \%$. Another significant finding is the positive linear association between the degree of severity of COPD and the prevalence of bronchiectasis, which is around $50 \%$ in severe cases, a higher figure than that found in healthy elderly people. The bronchiectasis found in COPD is usually cylindrical, situated in the base of the lungs and accompanied by thickening of the bronchial wall resulting from the inflammation associated with both diseases.

\section{What are the characteristics of patients with associated COPD and bronchiectasis?}

On the assumption that the two diseases are associated, beyond any overlapping prevalence due to the synchronic appearance of bronchiectasis for other reasons, patients with this association present several characteristics that differentiate them from COPD patients with no bronchiectasis. These differences are not limited to clinical factors but also involve functional, microbiological, inflammatory and even prognostic and therapeutic factors, which has led some authors to conclude that there is a specific clinical phenotype of COPD patients with bronchiectasis. Table 3 shows the results of the two meta-analyses published to date 28,29 . Patients with COPD associated with bronchiectasis present a lower value of post-bronchodilatory $\mathrm{FEV}_{1}$ and a higher probability of severe airway obstruction.

Of all these factors, perhaps the one most consistently reported is the presence of greater expectoration than usual; a higher number of exacerbations; a higher probability of chronic colonisation by potentially pathogenic microorganisms (PPM). As we shall see below, 
TABLE 3. Comparison between patients with COPD with and without bronchiectasis in two meta-analyses published in this respect

\begin{tabular}{|c|c|c|}
\hline & $\begin{array}{c}\text { Du et al. }(2016)^{25} \\
14 \text { studies }(n=5,329)\end{array}$ & $\begin{array}{l}\text { Ni et al. }(2015)^{24} \\
6 \text { studies }(n=881)\end{array}$ \\
\hline Bronchiectasis prevalence & $29 \%$ & $54.3 \%$ \\
\hline \multicolumn{3}{|l|}{ General characteristics } \\
\hline Males & - & OR: $1.62(1.15-2.28) ; p=0.006$ \\
\hline Age & - & WMD: 1.8 years $(0.05-3,55 ; p=0.04)$ \\
\hline Smoking history & - & WMD: 4.63 pack-years; $1.61-7.65 ; p=0.003$ ) \\
\hline \multicolumn{3}{|l|}{ Clinical parameters } \\
\hline More daily sputum production & - & OR: $2.30(1.66-3.19 ; p<0.00001)$ \\
\hline More exacerbations (previous year) & OR: $1.97(1.29-3)$ & WMD: $1.54(0.56-2.53 ; p=0.002)$ \\
\hline \multicolumn{3}{|l|}{ Lung function } \\
\hline Lower $\mathrm{FEV}_{1} / \mathrm{FVC}$ ratio & - & WMD: $-8.05 \%$ (-10.65 to -5.45$)$ \\
\hline Lower post-bd FEV 1 predicted severe airflow obstruction & OR: 1.31 (1.09-1.58) & WMD: $-11.06(-18.27$ to -3.85$)$ \\
\hline \multicolumn{3}{|l|}{ Systemic inflammatory markers } \\
\hline CRP level & -- & WMD: $6.11(0.26-11.95)$ \\
\hline Albumin level & -- & WMD: $-0.14(-0.23-0.06)$ \\
\hline \multicolumn{3}{|l|}{ Microbiological profile } \\
\hline Chronic PPM colonisation & OR: $3.76(2.37-5.96)$ & OR: 7.33 (4.61-11.67) \\
\hline Isolation $P$. aeruginosa & OR: $4.75(1.25-18.04)$ & OR: 3.59 (1.89-6.47) \\
\hline \multicolumn{3}{|l|}{ Prognostic parameters } \\
\hline Mortality & OR: 1.96 (1.04-3.70) & \\
\hline
\end{tabular}

Data are presented as Odds Ratio or Weighted Mean Difference (WMD); CRP: C-Reactive Protein; PPM: Potentially Pathogenic Microorganismsodds ratio (OR) or weighted mean difference (WMD).

CRP: C-reactive protein; $\mathrm{FEV}_{1}$ : forced expiratory volume in one second; FVC: forced vital capacity; post-bd: post bronchodilator test; PPM: potentially pathogenic microorganisms.

this concurs with the hypothesis that greater inflammation and chronic bronchial infection are a possible cause of this bronchiectasis. Along these lines, one study found that the probability of bronchiectasis in patients with severe COPD, chronic colonisation by PPM and multiple exacerbations was three times higher than that in patients without these characteristics (Fig. 1) ${ }^{20}$.

\section{Prognostic impact of bronchiectasis}

The presence of bronchiectasis has a marked impact on the vital prognosis of patients with COPD. Four studies have analysed this phenomenon to date. Of these, three found an increase in mortality (OR's between 2.15 and 3.96) after adjustment for different confounders $(15,30,31)$ but the fourth did not (odd ratio (OR): 1.05$)^{18}$. A recent meta-analysis concluded that COPD patients with bronchiectasis present double the mortality after adjustment for age, gender, body mass index and pulmonary function (adjusted OR: 196; 95\% CI: 1.04-3.70), but the studies in question were extremely heterogeneous and new ones are required to confirm this relationship ${ }^{29}$.

There has only been one study analysing the impact of bronchiectasis on the quality of life 


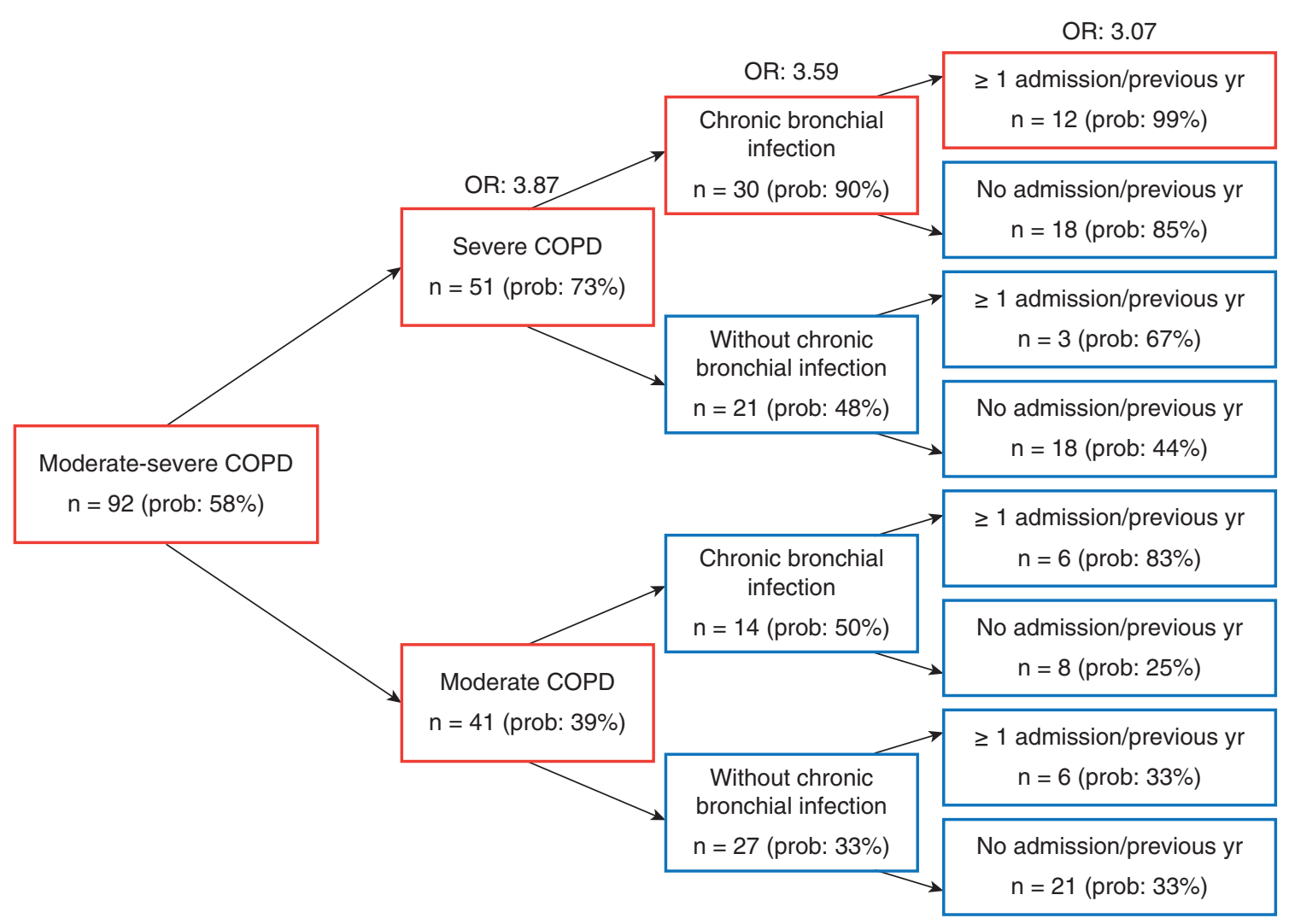

FIGURE 1. Variables associated with a greater prevalence of bronchiectasis in patients with COPD.

In red, COPD patients with high probability of presenting bronchiectasis.

COPD: chronic obstructive respiratory disease; OR: odds ratio; prev: prevalence; prob: probability; yr: year.

in patients with COPD. Tan et al. ${ }^{24}$, using the COPD Assessment Test (CAT) to evaluate quality of life, concluded that those patients with COPD and bronchiectasis had 1.89 (1.362.36; $\mathrm{p}<0.0001)$ more probability of having a CAT score $\geq 10$ than those without bronchiectasis, after adjusting by age, sex, body mass index, $\mathrm{FEV}_{1}$ and pack years.

Finally, one of the most consistently evident factors is the propensity of patients with bronchiectasis-associated COPD to have not only more exacerbations ${ }^{14-17}$ but also ones that are more severe $\mathrm{e}^{13,15,17,20}$ and longer-lasting ${ }^{9}$, although not all authors have found this association $^{18,19,24}$. Taken together, however, both the meta-analyses ${ }^{28,29}$ found a relationship between exacerbations and bronchiectasis (Table 3).

\section{Therapeutic implications}

The degree of scientific evidence for the various treatments commonly used in patients with COPD and/or bronchiectasis is very inconsistent. In the case of COPD, the various short- and long-term broncodilators and their combinations have been most widely documented, 
while in the case of bronchiectasis prolonged antibiotic treatment for chronic bronchial infection by $P$. aeruginosa and macrolides have been most fully studied (although bronchial dilators are extensively used in these patients, there has been little research on this topic). Respiratory rehabilitation is strongly supported by scientific evidence in both diseases, and this could be particularly effective in patients with both COPD and bronchiectasis, but treatments such as chromones, mucolytics, anti-leukotrienes and other anti-inflammatory drugs have barely been documented for either disease. Finally, there are other treatments, such as inhaled steroids, that are widely used but are still subject to great debate, so there is a tendency to prescribe them only on an individual basis ${ }^{7,8,32,33}$.

Regardless of the type of relationship between COPD and bronchiectasis in a specific patient with both diseases at the same time, it is widely agreed that the two diseases must be treated separately, as indicated by the international guidelines for both COPD and bronchiecta$\operatorname{sis}^{7,8,32,33}$. There are some specific circumstances that need to be taken into account, however:

Inhaled steroids. Some authors have observed that the use of inhaled steroids in COPD patients can lead to an increased incidence of pneumonia and other infections ${ }^{34}$. It therefore seems logical to suppose, despite the lack of any corroboratory scientific evidence - an interesting study would surely be welcome -, that care must be taken with inhaled steroid treatment in patients with not only COPD but also bronchiectasis, especially in situations of chronic bronchial infection by PPM. Inhaled steroids should be taken at minimum dose possible. One small clinical trial concluded that it is possible to decrease the dose of inhaled steroids (if the patient needs this treatment), combining it with long-acting beta 2 bronchodilators $^{35}$.

Macrolides. Macrolides at immunomodulatory doses have been shown to significantly reduce the number of exacerbations in patients with bronchiectasis ${ }^{36-38}$, and also, to a lesser extent, in patients with $\mathrm{COPD}^{39}$ his treatment could therefore be of special interest to those patients with both diseases, particularly when they involve multiple exacerbations. Other anti-inflammatory therapies such as phosphodiesterase 4 inhibitors may also be useful in this particular phenotype of patients.

Long-term inhaled antibiotics. Another interesting question is the possible prophylactic use of inhaled antibiotics in these patients in situations of chronic bronchial infection by PPM. These drugs are already widely used in patients with bronchiectasis (of all aetiologies), often with good results ${ }^{40,41}$, but there is barely any scientific evidence available regarding their use in COPD patients ${ }^{42}$. It is possible, however, that their administration in patients with COPD (outside any exacerbation period) and chronic bronchial infection (even without bronchiectasis) could represent an interesting line of research when it comes to evaluating these patients' progress, as well as avoiding the adverse effects and problems associated with the administration of systemic antibiotics.

\section{Is COPD-bronchiectasis a special phenotype of COPD patients?}

As mentioned above, the evidence available until now seems to indicate that the presence of bronchiectasis in COPD patients leads to 


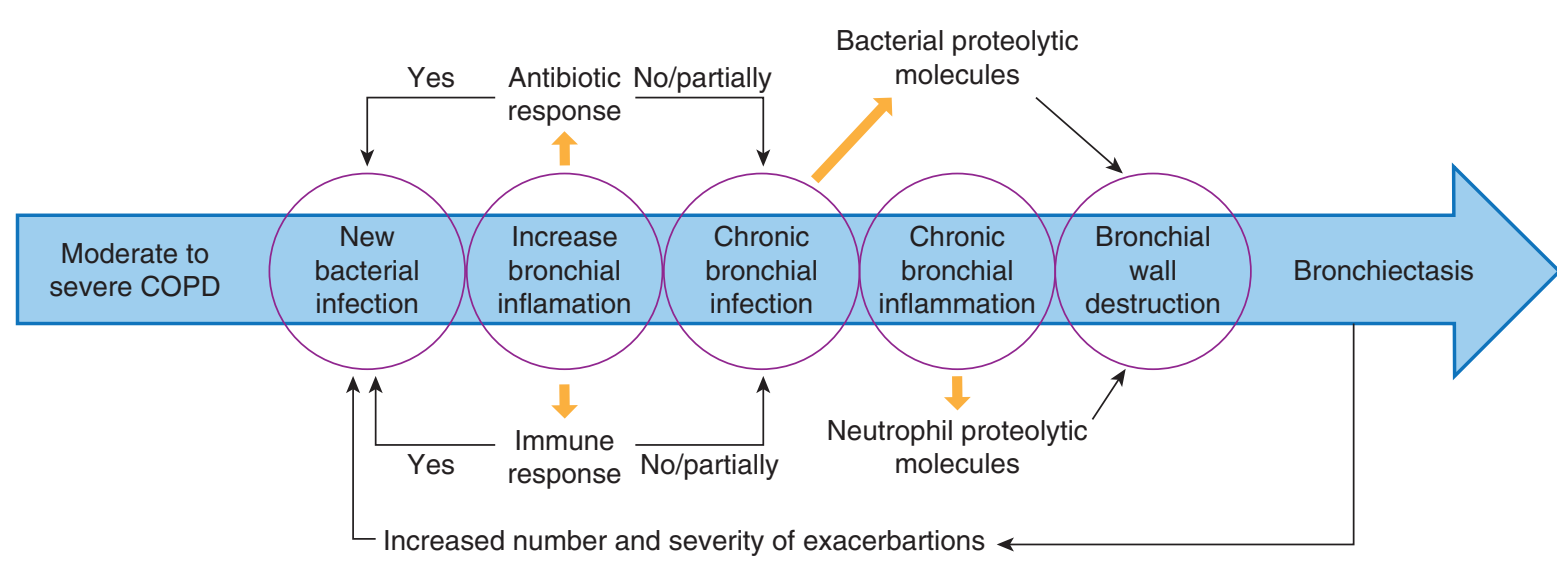

FIgURE 2. Pathophysiological hypothesis for the formation of bronchiectasis in patients with COPD.

COPD: chronic obstructive pulmonary disease.

greater clinical severity, more exacerbations, changes in therapeutic handling and possibly a poorer prognosis ${ }^{28,29}$. Deciding whether this information is sufficient to confirm the existence of a differential clinical phenotype is no easy task. On the one hand, it would be desirable to have more scientific evidence on the prognostic implications of bronchiectasis and the stability of this possible new phenotype over time; on the other hand, we need some better designed studies that analyse more homogeneous groups of patients. Nevertheless, this group of patients is already worthy of investigation, particularly as there is a theoretical possibility of preventing this association. As bronchiectasis due to COPD can occur in patients with previous chronic bronchial infection from PPM (which we could call the infectious phenotype), it is not far-fetched to suppose that treatment of this chronic infection could prevent the appearance of irreversible alterations (bronchiectasis) to the bronchial lumen. This theoretical infectious (or bronchiectasic) phenotype may be closely related to the well-known chronic bronchitis ${ }^{43}$ and exacerbator phenotypes of $\mathrm{COPD}^{44}$. Clinical studies are required in patients with COPD and chronic bronchial infection, using drugs such as inhaled antibiotics to confirm their efficacy in eradicating these microorganisms and, above all, improving these patients' evolution. Studies of biomarkers and genetics are also needed to answer questions such as: Why do not all COPD patients develop chronic bronchial infection? And why do not all patients with chronic bronchial infection develop bronchiectasis?

\section{Causal relationship}

Although it is a fact that most aetiological tables for bronchiectasis include COPD and asthma, no study has yet demonstrated any cause-effect relationship. Nevertheless, this is biologically plausible (Fig. 2). The appearance of a bacterial infection in patients with COPD (especially in its severest forms) will produce greater bronchial inflammation ${ }^{45}$. This situation, which can be perpetuated over time, 
is very likely to lead to more exacerbations ${ }^{46}$. In cases of exacerbation both the antibiotic treatment administered and the host immune system will often manage to eradicate the bacteria, or at least significantly reduce the number of colonies. When this does not occur, however, there may be chronic bronchial infection by $\mathrm{PPM}^{47}$. It has been known since the 1980s, through the pathogenic vicious circle described by Cole ${ }^{48,49}$, that this is the most common gateway to bronchiectasis resulting from chronic inflammation; to the production of proteolytic molecules by both bacteria and the neutrophils themselves; to the destruction of local defence systems and, therefore, the perpetuation of bronchial infection; and, finally, to the destruction of the bronchial wall, along with the dilatation of the bronchial lumen typical of bronchiectasis. Anyway, since a cause-and-effect relationship between COPD and bronchiectasis is still a hypothesis, we always have to rule out any cause of bronchiectasis in a COPD patient with bronchiectasis, as some guidelines have clearly stated, making all the complementary tests and collecting the specific clinical history in order to discover an alternative aetiology. It is only when an alternative aetiology does not exist that we can think of the possibility that this bronchiectasis has been caused by COPD itself.

Going beyond any pathophysiological hypothesis, there is a need to demonstrate "de novo" bronchiectasis in COPD patients that is not due to any other aetiologies in order to evaluate any possible causal relationship. This requires longitudinal studies with multiple HRCT over a period of time as well as investigation of the variables associated with the creation of new bronchiectasis, or the growth of pre-existing bronchiectasis. The basic problem with such studies is the possibility of a very prolonged timeframe (i.e., years) for any development of bronchiectasis.

\section{Future challenges}

The COPD-bronchiectasis phenotype, also known as the bronchiectasis-COPD overlap syndrome (BCOS), still poses an interesting scientific challenge ${ }^{50}$, as the studies performed today indicate that this is a special clinical subgroup of patients that could experience therapeutic and prognostic repercussions and could therefore, in the not too distant future, give rise to the development of specific drugs. Table 4 shows some of the interesting challenges posed by this association, some of which have already been discussed above.

\section{Bronchiectasis and emphysema}

There is very little information available about the relationship between emphysema (in the context of a patient with COPD not due to $\alpha 1-A T D)$ and bronchiectasis. It is well known that patients with significant emphysema can present traction bronchiectasis with few characteristic symptoms and little thickening of the bronchial wall. Beyond this, however, the two diseases can, to some extent, share a similar production mechanism (an imbalance between proteases and antiproteases), which makes their possible relationship worthy of investigation. Fugimoto et al. ${ }^{51}$ studied the radiological phenotype of $172 \mathrm{COPD}$ patients and found that more than $25 \%$ presented a combination of emphysema and bronchial wall thickening. These patients, compared to those in whom it was possible to identify only 
TABLE 4. Future challenges in the relationship between bronchiectasis and COPD

\begin{tabular}{|c|}
\hline What is the real prevalence of bronchiectasis in COPD patients? \\
\hline $\begin{array}{l}\text { What is the prognostic impact of the presence of bronchiectasis } \\
\text { in COPD patients? }\end{array}$ \\
\hline $\begin{array}{l}\text { Are the usual radiological criteria for bronchiectasis valid } \\
\text { in COPD patients? }\end{array}$ \\
\hline $\begin{array}{l}\text { What is the role of exacerbations and chronic bronchial infection } \\
\text { by PPM? }\end{array}$ \\
\hline Is COPD-bronchiectasis a different phenotype from COPD? \\
\hline Is COPD capable of triggering bronchiectasis? \\
\hline $\begin{array}{l}\text { Is bronchiectasis a mere comorbidity or just a phase in } \\
\text { the natural history of a COPD? }\end{array}$ \\
\hline $\begin{array}{l}\text { In which COPD patients should the presence of bronchiectasis } \\
\text { be ruled out? }\end{array}$ \\
\hline $\begin{array}{l}\text { Which pathophysiological mechanisms associate COPD with } \\
\text { bronchiectasis? }\end{array}$ \\
\hline How come not all COPD patients present bronchiectasis? \\
\hline $\begin{array}{l}\text { How come not all COPD patients present chronic bronchial } \\
\text { infection by PPM? }\end{array}$ \\
\hline What are the predictive biomarkers of bronchiectasis? \\
\hline $\begin{array}{l}\text { What is the role of anti-inflammatory drugs (macrolides or } \\
\text { phosphodiesterase } 4 \text { inhibitors) in these patients? }\end{array}$ \\
\hline Do inhaled steroids have a deleterious effect on these patients? \\
\hline What are the role and indications of inhaled antibiotics? \\
\hline $\begin{array}{l}\text { What role does the modification of the microbiome play in these } \\
\text { patients? }\end{array}$ \\
\hline $\begin{array}{l}\text { What is the pathophysiological association between } \\
\text { bronchiectasis and } \alpha 1 \text {-ATD? }\end{array}$ \\
\hline $\begin{array}{l}\text { Does inhaled and intravenous augmentation therapy help both } \\
\text { emphysema and airway disease in } \alpha 1 \text {-ATD? }\end{array}$ \\
\hline $\begin{array}{l}\text { What are the prevalence and impact of emphysema in } \\
\text { bronchiectasis? }\end{array}$ \\
\hline Should a future therapeutic approach target both components? \\
\hline
\end{tabular}

emphysema, presented a greater number of exacerbations and greater production of sputum. Other authors have studied this association in the opposite direction. Thus, Loubeyre et al. ${ }^{52}$ found radiological signs of emphysema in $45 \%$ of 90 patients with bronchiectasis who had never smoked. One particularly interesting finding was the appearance of bronchiectasis in the same segments of the lung as emphysema, along with an apparent correlation between the severity of the two diseases. The authors concluded that the emphysema found could be the consequence of the bronchial inflammation present in bronchiectasis, and that there could therefore be a causal relationship. Furthermore, Loebinger et al. ${ }^{53}$ observed in 91 patients with bronchiectasis that the presence of emphysema and thickening of the bronchial wall is independently associated with higher mortality (findings similar to those of Tang X et al. ${ }^{54}$ in 89 patients with bronchiectasis) and concluded that the presence of emphysema might be a result of inflammation in distal airways in response to the development of bronchiectasis, leading to a deterioration in lung function and a poorer prognosis.

\section{Bronchiectasis and alpha-1 antitrypsin deficiency and emphysema}

$\alpha 1-A T D$ is a genetic condition that predisposes to an early pulmonary emphysema. The prevalence and impact of this airway disease are greater than previously thought. Some reports have suggested an association, even a causal link, between emphysema and bronchiecta$\mathrm{sis}^{55}$. The prevalence of $\alpha 1-A T D$ in bronchiectasis is very low ${ }^{56-58}$. Conversely, the frequency of bronchiectasis in $\alpha 1-A T D$ is difficult to ascertain and varies from one study to another (27-60\%). Population-based bronchiectasis registries have not shown any great differences in alpha- 1 antitrypsin (AAT) allele frequencies, compared with control populations. The relationship between bronchiectasis and 
emphysema has a regional pattern underlying pathogenic processes since the presence of bronchiectasis was greater in lobes in which the emphysema score was higher ${ }^{59}$.

In a study published by Parr et al. ${ }^{59}$ in 74 patients with $\alpha 1$-ATD (PI*ZZ), CT bronchiectasis was found in 70 patients (95\%), whilst clinically significant disease, was only detected in 20 patients $(27 \%)$ being cylindrical bronchiectasis the most common morphological type. There was a correlation between greater bronchiectasis severity and more severe emphysema and between bronchial wall thickening and $\mathrm{FEV}_{1}$.

\section{BRONCHIECTASIS AND ASTHMA}

\section{Prevalence of bronchiectasis in asthmatic patients}

Leaving aside allergic bronchopulmonary aspergilosis, whose characteristics include the presence of asthma and central bronchiectasis, several studies have found a greater prevalence of bronchiectasis in patients with asthma (especially when this is severe or difficult to control). When the radiological definition of bronchiectasis is taken as a presence of a broncho-arterial quotient greater than 1 , its prevalence is $30-40 \%$. This type of bronchiectasis is usually cylindrical and found in the bases of the lungs, and it is mainly associated with thickening of the bronchial wall that reveals the existence of unresolved bronchial inflammation ${ }^{60-65}$.

\section{Bronchiectasis and asthma. A pathophysiological hypothesis}

Bronchiectasis is traditionally considered to be the result of structural damage caused by a chronic bronchial infection and subsequent inflammation. It is possible that this is not the only mechanism, however. It seems that while the presence of inflammation (and its consequences) is a condition sine que non for the appearance of bronchiectasis, this is not the case with bronchial infection ${ }^{49}$. Thus, patients with rheumatoid arthritis, or those in the early phases of cystic fibrosis with no bronchial infection, may already present bronchiectasis. As regards asthma (especially in its most severe forms), an analysis of the various studies that have examined the structural bronchial damage in this disease show a clear increase in both the prevalence of bronchiectasis and the thickness of the bronchial wall (as a result of the substantial bronchial inflammation that is usually present) ${ }^{60-66}$. There is no evidence to date, however, of any abnormal isolation of potentially pathogenic microorganisms (although this has not been specifically studied). All in all, it is still not clear to what extent the pathophysiological hypothesis causally linking severe asthma with bronchiectasis is wellfounded, or to what extent bronchiectasis is just another comorbidity in these patients. It has also been suggested that there are other mechanisms, such as microaspirations and gastro-oesophageal reflux, that could be intermediary factors between asthma and bronchiectasis.

\section{Impact of bronchiectasis on asthma}

Various authors have observed that bronchiectasis is found in the severest clinical and functional forms of asthma, generally concomitant with predominantly neutrophilic inflammation $^{60}$ or emphysema, or with a current or previous smoking habit ${ }^{64}$. Bronchiectasis is 
also often seen in long-term, non-allergic asth$\mathrm{ma}^{60,64}$, which represents a greater therapeutic burden but nevertheless presents more exacerbations ${ }^{66}$. All these characteristics could jointly form a special clinical phenotype of asthma patients. Table 5 shows the characteristics of asthma patients that are currently known to be associated with the appearance of bronchiectasis. It must be stressed that, although bronchiectasis is associated with forms of asthma with greater airway obstruction, this does not mean that bronchiectasis is necessarily associated with airway obstruction, and so the latter is not a pre-condition for its diagnosis.

\section{Future challenges}

It is clear that the information available in the literature at the moment is very scanty and only covers transversal studies aimed at establishing the prevalence of bronchiectasis or some of these patients' characteristics. Longitudinal studies are therefore required to find stronger links between the two diseases and possible shared pathophysiological mechanisms, and, above all, to assess the impact of bronchiectasis on asthma patients, as this probably has prognostic and therapeutic implications. Many questions remain unanswered: What is the real prevalence of bronchiectasis in asthma patients? What is the role of bronchiectasis in the asthma-COPD overlap syndrome (ACOS)? Does the severity or management of asthma affect the presence of bronchiectasis? Could the eosinophil play a role in the genesis of bronchiectasis? Is this an association or is there a causal relationship? In which asthma patients should the presence of bronchiectasis be ruled out? And in which asthma
TABLE 5. Characteristics of asthma patients with greater probability of presenting bronchiectasis

\begin{tabular}{|l}
\hline Smoker or ex-smoker \\
\hline More neutrophils in the sputum \\
\hline Longer duration of the disease \\
\hline Older age \\
\hline Poorer pulmonary function \\
\hline Greater number of exacerbations \\
\hline Greater need for steroids and bronchodilators \\
\hline Non-allergic asthma \\
\hline Greater degree of radiological emphysema \\
\hline Asthma clinically described as severe (the more severe it is, \\
the greater the presence of bronchiectasis)
\end{tabular}

patients should the presence of bronchiectasis be ruled out? The current use of low-radiation algorithms for HRCT without any loss of diagnostic capacity provides an extraordinary opportunity to delve further into a topic of great scientific interest and clear practical implications.

\section{CONFLICT OF INTEREST}

The authors have nothing to disclose.

\section{REFERENCES}

1. Kwak HJ, Moon JY, Choi YW et al. High prevalence of bronchiectasis in adults: Analysis of CT findings in a health screening program. Tohoku J Exp Med. 2010;222:237-42.

2. Whitters D, Stockley RA. Bronchiectasis in older patients with chronic obstructive pulmonary disease. Drugs Aging. 2013;30:215-25.

3. McElvaney NG, Stoller JK, Buist AS et al. Baseline characteristics of enrollees in the National Heart, Lung and Blood Institute Registry of alpha-1 antitrypsin deficiency. Alpha-1 Antitrypsin Deficiency Registry Study Group. Chest. 1997;111:394-403.

4. Lujan M, Gallardo X, Amengual MJ et al. Prevalence of bronchiectasis in asthma according to oral steroid requirement: Influence of immunoglobulin levels. BioMed Research International. 2013; Article ID 109219. http://dx. doi.org/10.1155/2013/109219.

5. Agustí A, Bel E, Thomas M et al. Treatable traits: towards precision medicine of chronic airway diseases. Eur Respir J. 2016;47:410-9. 
6. Naidich DP, McCauley DI, Khouri NF et al. Computed tomography of bronchiectasis. J Comput Assist Tomogr. 1982;6:437-44.

7. Vendrell M, de Gracia J, Olveira C et al. Diagnóstico y tratamiento de las bronquiectasias. Arch Bronconeumol. 2008;44:629-40.

8. Global Strategy for the Diagnosis, Management and Prevention of Chronic Obstructive Lung Disease. Report 2017. Available from: htttp://goldcopd. org/gold-2017-global-strategy-diagnosis-management-prevention-copd/

9. Patel IS, Vlahos I, Wilkinson TM et al. Bronchiectasis, exacerbations indices, and inflammation in chronic obstructive pulmonary disease. Am J Respir Crit Care Med. 2004;170:400-7.

10. Roche N, Kouassi B, Rabbat A et al. Yield of sputum microbiological examination in patients hospitalized for exacerbations of chronic obstructive pulmonary disease with purulent sputum. Respiration. 2007;74:19-25.

11. Garcia-Vidal C, Almagro P, Romaní V et al. Pseudomonas aeruginosa in patients hospitalised for COPD exacerbations: a prospective study. Eur Respir J. $2009 ; 34: 1072-8$

12. Agusti A, Calverley PM, Celli B et al. Evaluation of COPD Longitudinally to Identify Predictive Surrogate Endpoints (ECLIPSE) investigators. Characterization of COPD heterogeneity in the ECLIPSE cohort. Respir Res. 2010;11:122-36.

13. Arram EO, Elrakhawy MM. Bronchiectasis in COPD patients. Egyptian Journal of Chest Diseases and Tuberculosis. 2012;61:307-12.

14. Steward JI, Maselli DJ, Anzueto A. Clinical impact of CT radiological feature of bronchiectasis in the COPDGene Cohort. Am J Respir Crit Care Med. 2012;185:A3656.

15. Martínez-García MA, de la Rosa Carrillo D, Soler-Cataluña JJ et al. Prognostic value of bronchiectasis in patients with moderate-to-severe chronic obstructive pulmonary disease. Am J Respir Crit Care Med. 2013;187: 823-31

16. Tulek B, Kivrak AS, Ozbek S et al. Phenotyping of chronic obstructive pulmonary disease using the modified Bhalla scoring system for high-resolution computed tomography. Can Respir J. 2013;20:91-6.

17. Gatheral T, Kumar N, Sansom B et al. COPD-related bronchiectasis; Independent impact on disease course and outcomes. COPD. 2014;00;1-10.

18. Jairam PM, van der Graaf $Y$, Lammers JWJ et al. Incidental findings on chest $\mathrm{CT}$ imaging are associated with increased COPD exacerbations and mortality. Thorax. 2015;70:725-32.

19. Bafadhel M, Umar I, Gupta S et al. The role of CT scanning in multidimensional phenotyping of COPD. Chest. 2011;140:634-42.

20. Martínez-García MÁ, Soler-Cataluña JJ, Donat Sanz Y et al. Factors associated with bronchiectasis in chronic obstructive pulmonary disease patients. Chest. 2011;140:1130-7.

21. Gallego M, Pomares X, Espasa M et al. Pseudomonas aeruginosa isolates in severe chronic obstructive pulmonary disease: characterization and risk factors. BMC Pulm Med. 2014;14:103.

22. Mao B, Lu HW, Li MH et al. The existence of bronchiectasis predicts worse prognosis in patients with COPD. Scientific Reports. 2015;5:10961.

23. Doria da Silva SM, Paschoal IA, De Capitani EM et al. COPD phenotypes on computed tomography and its correlation with selected lung function variables in severe patients. Int J Chron Obst Pulm Dis. 2016;11:503-13.

24. Tan WC, Hague CJ, Leipsic J et al. Canadian Respiratory Research Network and the CanCOLD Collaborative Research group. Findings on Thoracic Computed Tomography Scans and Respiratory Outcomes in Persons with and without Chronic Obstructive Pulmonary Disease: A Population-Based Cohort Study. PLoS One. 2016;11:e0166745.

25. Hurst JR, Elborn JS, De Soyza A et al. COPD-bronchiectasis overlap syndrome. Eur Respir J. 2015;45:310-3.

26. Martínez-García MA, Maiz L, de la Rosa D. The overlap between COPD and bronchiectasis. Eur Respir Mon. 2015;6:96-109.

27. Martinez-Garcia MA, Selma-Ferrer MJ, Navarro-Soriano C et al. Bronchiectasis phenotype in COPD patients. Clin Pulm Med. 2015;22:123-7.

28. Ni Y, Shi G, Yu Y et al. Clinical characteristics of patients with chronic obstructive pulmonary disease with comorbid bronchiectasis: a systematic review and meta-analysis. Int J Chron Obst Pulm Dis. 2015;10:1465-75.
29. Du Q, Jin J, Liu X, Sun Y. Bronchiectasis as a comorbidity of chronic obstructive pulmonary disease: A systematic review and meta-analysis. PlosOne. 2016;15:0150532.

30. Sadigov AS, Akhundov S. Bronchiectasis associated with COPD: does it increase the mortality rate in patients with severe disease? Am J Respir Crit Care Med. 2014;189:A4257.

31. Katsura H, Ogata M, Kida K. Factors determining outcome in elderly patients with severe COPD on long-term domiciliary oxygen therapy. Monaldi Arch Chest Dis 2001;58:195-201.

32. Pasteur MC, Bilton D, Hill AT. British Thoracic Society Bronchiectasis nonCF Guideline Group. British Thoracic Society guideline for non-CF bronchiectasis. Thorax. 2010;65 Suppl 1:i1-58.

33. Miratvilles M, Calle M, Soler-Cataluña JJ. Fenotipos clínicos de la EPOC. Identificación, definición e implicaciones para las guías de tratamiento. Arch Bronconeumol. 2012;48:86-98.

34. Kew KM, Seniukovich A. Inhaled steroids and risk of pneumonia for chronic obstructive pulmonary disease. Cochane Database Syst Rev. 2014;10:CD010115

35. Martínez-García MA, Soler-Cataluña JJ, Catalán-Serra P et al. Clinical efficacy and safety of budesonide-formoterol in non-cystic fibrosis bronchiectasis. Chest. 2012;141:461-8.

36. Serisier DJ, Martin ML, McGuckin MA et al. Effect of long-term, low-dose erythromycin on pulmonary exacerbations among patients with non-cystic fibrosis bronchiectasis: the BLESS randomized controlled trial. JAMA. 2013; 309:1260-7.

37. Altenburg J, de Graaff CS, Stientra Y et al. Effect of azithromycin maintenance treatment on infectious exacerbations among patients with non-cystic fibrosis bronchiectasis: the BAT randomized controlled trial. JAMA 2013;309:1251-9.

38. Wong C, Jayaram L, Karalus $\mathrm{N}$ et al. Azithromycin for prevention of exacerbations in non-cystic fibrosis bronchiectasis (EMBRACE) : a randomized, double-blind, placebo-controlled trial. Lancet. 2012;380:660-7.

39. Albert RK, Connet J, Bailey WC et al. Azithromycin for prevention of exacerbation of COPD. N Engl J Med. 2011;365:689-98.

40. Brodt AM, Stovold E, Zhang L. Inhaled antibiotics for stable non-cystic fibrosis bronchiectasis: a systematic review. Eur Resp J. 2014;44:382-93.

41. Chalmers JD, Aliberti, Blasi F. State of the art review: management of bronchiectasis in adults. Eur Resp J. 2015;45:1446-62.

42. Dal Negro R, Micheletto C, Tognella S et al. Tobramycin nebulizer solution in severe COPD patients colonized with Pseudomonas aeruginosa: effects on bronchial inflammation. Adv Ther. 2008;25:1019-30.

43. Kim V, Criner GJ. The chronic bronchitis phenotype in chronic obstructive pulmonary disease: features and implications. Curr Opin Pulm Med. 2015;21:133-41

44. Wedzicha JA, Brill SE, Allinson JP, Donaldson GC. Exacerbartor COPD. Mechanisms and impact of the frequent exacerbator phenotype in chronic obstructive pulmonary disease. BMC Med. 2013;14;11:181.

45. Soler N, Ewig S, Torres A et al. Airway inflammation and bronchial microbial patterns in patients with stable chronic obstructive pulmonary disease. Eur Resp J. 1999;14:1015-22.

46. Gompertz S, O'Brien C, Bayley DL et al. Changes in bronchial inflammation during acute exacerbations of chronic bronchitis. Eur Respir J. 2001;17:1112e9.

47. Matkovic Z, Miravitlles M. Chronic bronchial infection in COPD. Is there an infective phenotype? Respir Med. 2013;107:10-22.

48. Cole PJ. Inflammation: a two edged-sword-the model of bronchiectasis. Eur J Respir Dis. 1986;69:Suppl.147,6-15.

49. Fuschillo S, De Felice A, Balzano G. Mucosal inflammation in idiopathic bronchiectasis: cellular and molecular mechanisms. Eur Respir J. 2008;31:396-406

50. Hester KLM, McDonnell M, De Soyza A. Bronchiectasis: What we don' know yet but should. BRN Rev. 2016;2:14-26.

51. Fugimoto K, Kitagughi Y, Kubo K et al. Clinical analysis of chronic obstructive pulmonary disease phenotypes classified using high-resolution computed tomography Respirology. 2006;11:731-40.

52. Loubeyre P, Paret M, Revel D, Wiesendanger T et al. Thin-Section CT Detection of Emphysema Associated With Bronchiectasis and Correlation With Pulmonary Function Tests. Chest. 1996;109:360-5. 
53. Loebinger MR, Wells AU, Hansell DM et al. Mortality in bronchiectasis: A long-term study assessing the factors influencing survival. Eur Respir J. 2009;34:843-9.

54. Tang X, Bi J, Yang D, Chen S et al. Emphysema is an independent risk factor for 5-year mortality in patients with bronchiectasis. Clin Respir J. 2015 Dec 10. doi: 10.1111/crj.12432. [Epub ahead of print].

55. King MA, Stone JA, Diaz PT et al. Alpha-1 antitrypsin deficiency: evaluation of bronchiectasis with CT. Radiology. 1996;199:137-41.

56. Lonni S, Chalmers JD, Goeminne PC et al. Etiology of non-cystic fibrosis bronchiectasis in adults and its correlation to disease severity. Ann Am Thorac Soc. 2015;12:1764-70.

57. Olveira C, Padilla A, Martinez-Garcia MA et al. Etiology of bronchiectasis in a cohort of 2047 patients. An analysis of the historical Spanish Registry of Bronchiectasis. Arch Bronconeumol. 2017 (in press).

58. Gao YH, Guan WJ, Liu SX et al. Aetiology of bronchiectasis in adults: A systematic literature review. Respirology. 2016;21:1376-83.

59. Parr DG, Guest PG, Reynolds JH et al. Prevalence and impact of bronchiectasis in alpha-1 antitrypsin deficiency. Am J Respir Crit Care Med. 2007; 176:1215-21.
60. Gupta S, Siddiqui S, Haldar P et al. Qualitative analysis of High-Resolution CT scans in severe asthma. Chest. 2009;136:1521-8.

61. Walker C, Gupta S, Hartley R et al. Computerized tomography scans in severe asthma: Utility and clinical implications. Curr Opin Pulm Med. 2012; 18:42-7.

62. Grenier P, Mourey-Gerosa I, Benali K et al. Abnormalities of the airways and lung parenchyma in asthmatics: CT observations in 50 patients and inter- and intraobserver variability. Eur Radiol. 1996;6:199-206.

63. Lynch DA, Newell JD, Tschomper BA et al. Uncomplicated asthma in adults: comparison of CT appearance of the lungs in asthmatic and healthy subjects. Radiology. 1993;188:829-33.

64. Paganin F, Sénetérre E, Chanez P et al. Computed tomography of the lungs in asthma: Influence of disease severity and etiology. Am J Respir Crit Care Med. 1996;153:110-4.

65. Bumbacea D, Campbell D, Nguten L et al. Parameters associated with persistent airflow obstruction in chronic severe asthma. Eur Respir J. 2004; 24:122-8.

66. Kang HR, Choi GS, Park SJ et al. The effects of bronchiectasis on asthma exacerbations. Tuberc Respir Dis. 2014;77:209-14. 